\title{
TQM, maintenance and plant availability
}

\author{
David J. Sherwin and Patrik Jonsson \\ Växjö University, Växjö, Sweden
}

\section{Review of current production planning and control systems}

The present generation of manufacturing planning and control systems (MPCS) deal well with the planning and control of daily production and costs. All work well in static situations and some are able to adjust plans in real time. M RP II, JIT, order point system (OPS) and make-to-order systems are more or less suitable in different environments.

Most large manufacturing companies and some small ones use manufacturing resource planning (M RP II), a computerized model to plan material supply and production operations based on forecasting and simulation models that optimize expected profit[1]. MRP II is best suited to mass production of complex items, with fairly predictable logistics and demand[2,3].

The latest fad is just-in-time/K anban. The concept started life as the Toyota Production System. Under JIT one produces the smallest possible quantities at the latest possible time based on order, implying 100 per cent quality and no inventories[4,5]. JIT has become popular recently, especially in the USA [2,3]. One of the best-known JIT plants is NUMMI, a General Motors carmanufacturing plant in Fremont, California. NUMMI halved man-hours per vehicle to 20.8 and improved morale[6]. JIT works best with low product complexity, small set-up costs, and short production and purchasing lead times, but fails in the absence of full T QM .

The very simple order point system is used by about 25 per cent of companies including most small ones[2,3]. Stocks of materials, parts and products vary between fixed limits based on past demand and lead times. It suits low-tech products with small set-up costs and stable demand. It is a development of the even simpler make-to-order system in which nothing is done or ordered until an order for goods is received.

Optimized production technology (OPT) is a computer system from Israel based on mathematical programming, simulation and critical path analysis. OPT focuses on production rather than material planning and suits very complex environments.

\section{Review of current maintenance systems}

Maintenance as a proportion of production costs averages 15 per cent (11-30 per cent) in the Swedish manufacturing industry[7]. This is obviously too big to omit from the MPCS, but today's systems do not specifically include maintenance, although it is not completely disregarded. Many firms have 
JQME

1,1

16

recently been beguiled by one of the two maintenance fads - total productive maintenance (TPM) and reliability-centred maintenance (RCM).

Total productive maintenance (TPM) aims to reduce failures, set-ups, and other causes of poor or reduced production by involving the operators in the maintenance of their machines, as an integral part of the T QM philosophy[8]. It was, by Nakajima's own admission, originally proposed for JIT, where you cannot plan maintenance because of erratic demand on the machine. It relies, for the success that it has had, on the fact that many failures to machines are caused by lack of primary care (greasing, spannering and cleaning). The problems come later, when failures occur which can be suppressed by preventive maintenance (PM), but cannot be alleviated by the efforts of the operator. Perhaps in Japan it is possible to renew plant before the lack of secondary maintenance becomes too obvious, but this method would probably not be satisfactory in the West, particularly if demand for the product was increasing just as PM was due. TPM does not exclude PM, but there is no specific strategy in it to allow PM to be planned and so it is almost bound to be neglected if the factory gets too busy and will, at best, be irregular.

Reliability-centred maintenance (RCM) purports to find the correct PM schedule[9]. It has its origins in the operational research (OR) models of the Second World War[10], but M oubray's book gives actually a rather simplistic interpretation of the standard maintenance models for A ge, Block and Oncondition maintenance which fudges the data issue. Its best feature is the involvement of the operators and maintainers in the reassessment of maintenance needs. Its most dramatic successes have been obtained when plant has previously been grossly over-maintained (e.g. civil aircraft) or overmaintained in some areas and under-maintained in others (e.g. oil production platforms). It is also quite effective at highlighting plant which frequently fails through over-stress or abuse. How ever, RCM does not fully recognize that maintenance is an economic problem at the machine or plant level. It uses many well-established techniques such as FMECA/design audit, brainstorming and small group dynamics. It improves existing plant instead of getting future plants right, and makes junior staff responsible for assessing failure criticalities. It seeks to avoid the requirement of a maintenance system based truly on reliability for accurate and complete data analysed in a modern maintenance management information system (M MIS). These subjective judgements by junior staff can be wrong, but Moubray offers no corrective mechanism; we have to wait for the disaster to occur.

TPM and RCM advertise vast savings for little investment, which are not obtainable if the organization is al ready efficient. Short-term gains may precede long-term grief. TPM and RCM should be augmented by a PM policy based on failure-time distributions, inspection frequencies and costs. In fact, they may be usefully regarded as stop-gaps until such a scientifically based system can be set up and produce enough data to optimize the schedules and identify the design faults. Complete history and costs are also needed for better renewal and overhaul decisions. Neglect of the preventive maintenance planning is a great 
disadvantage in any manufacturing system. This is especially true for a JIT system in which the inventories are decreased to a minimum and the material flow is dependent on a plant without breakdowns. If such a system is ever going to reach perfect one-at-a-time manufacturing, there is no time for failed or wasted parts or standstill. Maintenance, the key success factor, is ironically excluded from the managerial IT system.

To get a further understanding of the value of strategic maintenance, it is appropriate to look at the life cycle profit (LCP) concept[7]. A II estimated cash flows that will occur during the whole plant life cycle are reduced to NPV and totalled. It seems to be universally acknowledged now that some conditionbased and periodic preventive maintenance is desirable to reduce total life-cycle costs and get the best out of machinery. This will provide a reasonably good basis for the introduction of the life cycle profit concept, but LCP cannot yet be said to be accepted practice. Proper use of LCP depends as much on PM schedule optimization, including renewals of components and machines, inspections, condition monitoring and overhauls, as it does on integration with other functions. In this area, we can see two problems with the systems of today. First, maintenance is seldom integrated into the company's management information system (MIS); in fact even local systems seldom exist which can provide the data needed for optimizations. In most companies, maintenance is run from a separate PC with little or no exchange of data with associated systems for stores and finance, using a simple, proprietary program that does no more than bring up, plan and record. Even when enough has been invested in maintenance to have a favourable effect on unit costs, production takes the credit and at once sets about trying to gain more by reducing the very same maintenance time that produced the advantage. The computer-integrated manufacturing (CIM) systems now in use encompass the whole product cycle from design, through resource planning to manufacture, but they do not encompass any maintenance. Second, there is a great gulf between the theoreticians and the practitioners, which ensures that even the more practical OR models are not widely applied. Barlow[11] reminds us that, in the 1940s and 1950s, mathematical theory of reliability, concerning renewal theory, reliability tests, failure rate estimates, fatigue life in material, etc., was already well advanced; these theories could contribute to the maintenance planning of today.

E ven when data are reasonably complete, there are many pitfalls to be avoided in analysis. To illustrate this point, readers are referred to a previous paper[12], in which it was shown that, when maintenance is badly carried out, and the data are poorly discriminated, it is possible to obtain Weibull analyses which seem to indicate a decreasing hazard rate. It was shown that the data were in fact probably bi-modal, the early failures being due to poor quality workmanship or sub-standard spare parts. Even though the causes of bad work were not tackled in this case (by retraining the technicians), substantial gains in plant availability and profitability were achieved by the reintroduction of periodic planned preventive maintenance schedules which had been abandoned on the grounds that the hazard rates were falling, at the instigation of the OR 
JQME 1,1

department. Poor maintenance work should be suspected if the serial correlation of the failures in calendar time shows them arriving in bunches. This is a sure indication that something went wrong at the first maintenance or renewal of each bunch and took two or three attempts to get right, possibly more by chance than good management.

\section{Integrating maintenance into production planning and control}

Manufacturing, and the maintenance of manufacturing plant, is far more complex today than a few years ago and we believe that it will be even more complex in the future. $M$ anufacturing will become as intensive as continuous process production is nowadays, driven by the relentless pursuit of cost reductions, and will therefore need a maintenance system that works. To get this, we have to stop the battle between production and maintenance, by broadening the perspective of maintenance and integrating the two systems into a complete market-oriented system.

The needs of such an integrated system are:

(1) T QM . A prerequisite for advanced methodology in maintenance and the integration of the function with production is the existence of a modern T QM system under a committed management. The current ruling philosophy of management by objectives (MBO)[13] should be abandoned in favour of old-fashioned leadership by example. Otherwise it will be difficult to implement successfully any small group activities such as the maintenance groups advocated under TPM and RCM. Training, as well, is likely to become essential to achieve an integrated system. A t every level, people will need to learn the latest techniques of management, control and the technology of maintenance, as well as specific training in operation and maintenance of the latest machines. It is vital to both productivity and quality that maintenance work be of a high technical standard. Maintenance will always include diagnosis of the unexpected fault. This requires intelligent, educated and trained people.

(2) Feedback system. Feedback to designers of detailed reliability data and running conditions of machinery is essential to the rapid development of reliability in successive evolutionary designs. A t present this is only done properly in the aircraft industry. M ost companies use the supplier's estimates in calculating life-cycle costs for equipment choice, which is simply naïve without attested evidence from other users.

(3) M IS. A n integrated information system is essential if the data needed for true reliability-based maintenance schedule optimization are to be generated economically. The system should allow numerical data on costs to be gathered on each job from the stores and wages modules and the production losses, and then matched unequivocally with running data and failure descriptions, preferably automatically. This is mostly a matter of arranging for the data to be "cut" in many different ways to suit 
the purposes of finance, production costing and planning, and maintenance optimization.

TQM,

(4) PM schedules. Improved preventive maintenance schedules could then be based on facts rather than fancies or incomplete data. The proper way to improve schedules is to accumulate enough good data to optimize schedules for redesign, age/block renewal of components, conditionbased maintenance and the OR models used to choose between overhaul maintenance and plant availability and renewal. However, it takes time to accumulate enough data for optimizations to be statistically viable, so start with makers' or present schedules.

PM scheduling would make a great contribution to an M RP II system, in which PM can be integrated into the plan. It could occur with minimum disruption and no surprises. With the JIT system, however, there will be problems because it is demand-led and therefore essentially unpredictable. JIT may demand levels of reliability which are economically unattainable without redundancy. We wonder whether it will generally be more economic than to have redundancy or to go back to buffer stocks or to switch to MRP II. Without collecting and analysing data it will not be possible to know.

\section{References}

1. Wight, O.W., M anufacturing Resource Planning: MRP II - Unlocking A merica's Productivity Potential, Oliver Wight Publications, Essex Junction, VT, 1981.

2. New man, W. and Sridharan, V., "Manufacturing planning and control: is there one definitive answer?", Production and Inventory M anagement Journal, 1st Quarter, 1992.

3. Mattsson, S.A ., M aterialplaneringsmetoder i Svensk Industri (Translation: $M$ aterial Control M ethods in the Swedish Industries), The Institute for Transport Economics and Business Logistics, University of Växjö, Sweden, 1994.

4. O'Grady, A ., Putting the Just-in-T ime Philosophy into Practice, Kogan Page, London, 1988.

5. Hay, E.J., T he Just-in-T ime Breakthrough - Implementing the New M anufacturing Basics, John Wiley \& Sons, New York, NY, 1988.

6. A dler, P.S. and Coyle, R.E., "Designed for learning: a tale of two auto plants", Sloan M anagement Review, Spring 1993, pp. 85-94.

7. A hlmann, H., LCC/LCP T heory and Case Studies, Compendium, Department of Industrial Management, Lund Institute of Technology, Lund, 1994, pp. 811-13.

8. Nakajima, S., TPM - An Introduction to Total Productive M aintenance, Productivity Press, Cambridge, MA , 1988.

9. Moubray, J., Reliability-centred M aintenance, Butterworth-Heinemann, Oxford, 1991.

10. Villemeur, A., Reliability, A vailability, M aintainability and Safety A ssessment, John Wiley \& Sons, Chichester, 1991.

11. Barlow, R.E., "Mathematical theory of reliability: a historical perspective", IEEE Transactions on Reliability, Vol. R-33 No. 1, A pril 1984, pp. 16-20.

12. Sherwin, D.J. and Lees, F.P., "A $n$ investigation of the application of failure data analysis to decision making in maintenance of process plants" (in two parts), Proceedings of the Institute of Mechanical Engineers, Vol. 194 No. 29, 1980.

13. Deming, W.E., Out of the Crisis, Cambridge University Press, Cambridge, MA , 1986. 